\title{
FORMAS DE MECANIZAÇÃO E MANEJO DO SOLO PARA A CULTURA DA BATATA I - CARACTERÍSTICAS DA PRODUÇÃO
}

\author{
SIDNEI O. JADOSKI ${ }^{1}$, LARISSA R. SAITO ${ }^{2}$, MARCIO F. MAGGI ${ }^{3}$, \\ MARCOS V. WAGNER ${ }^{4}$, TAIÃ N. REFFATTI ${ }^{5}$
}

\begin{abstract}
RESUMO: O objetivo da pesquisa foi estudar os efeitos do manejo com diferentes formas de preparo do solo, tipos de resteva e infestação do solo com Trichoderma harzianum sobre a produtividade e as características dos tubérculos da cultura da batata. $\mathrm{O}$ experimento foi estruturado em delineamento inteiramente casualizado, em parcelas subsubdivididas, em um esquema fatorial $4 \times 5 \times 2$, com quatro repetições. Foram avaliadas, na parcela, as seguintes formas de preparo do solo: preparo-base (escarificação e sulcamento) - P1; preparo-base mais grade niveladora - P2; preparo-base mais enxada rotativa - P3, e preparo-base mais grade niveladora e enxada rotativa P4. Na subparcela, utilizaram-se as restevas de aveia, milho, trigo, feijão e uma testemunha sem resteva. A subsubparcela constitui-se da infestação ou não infestação de T. harzianum no solo. Concluiu-se que a menor mobilização do solo ocasiona maior produtividade da cultura. $\mathrm{O}$ preparo convencional do solo para o cultivo da batata pode ser reduzido, eliminando-se as operações com enxada rotativa ou grade niveladora. A aplicação das restevas exerceu efeito positivo para o incremento da produtividade de tubérculos. $\mathrm{O}$ efeito da presença do fungo $T$. harzianum afetou negativamente a qualidade do tubérculo, sem exercer efeito significativo sobre a produtividade da cultura, demonstrando a necessidade de ser mais bem estudado.
\end{abstract}

PALAVRAS-CHAVE: preparo do solo, tipos de resteva, produtividade, Trichoderma harzianum.

\section{FORMS OF MECHANIZATION AND SOIL MANAGEMENT FOR THE POTATO CULTURE I - CHARACTERISTICS OF PRODUCTION}

\begin{abstract}
The aim of the research was to study the effects of management with different forms of tillage, stubble and types of infestation of soil with Trichoderma harzianum on the characteristics of components of the canopy of the potato crop, production and characteristics of tubers produced. The experiment was structured in a randomized design in split plots in a factorial $4 \times 5 \times 2$ with four replications. It was evaluated, in plots, the following forms of tillage: tillage base (and chisel plowing) - P1, base tillage more harrowing - P2, rotary hoe most basic preparation and P3 base most harrowing and rotary hoe - P4. In the subsections it was used the stubble of oats, corn, wheat, beans and a control without stubble. The sub subplot constitutes of no infestation or infestation of $T$. harzianum in soil. It was concluded that less tillage causes greater crop yield, and that the application of stubble positive effect for increasing productivity, especially corn and wheat. The effect of $T$. harzianum to the potato yield was not significant, demonstrating the need for further studies.
\end{abstract}

KEYWORDS: tillage, stubble types, productivity, reduced growth.

\footnotetext{
${ }^{1}$ Eng ${ }^{\mathrm{o}}$ Agrônomo, Prof. Dr., Departamento de Agronomia, Universidade Estadual do Centro Oeste, Unicentro, Guarapuava - PR, sjadoski@unicentro.br.

${ }^{2}$ M.Sc., Programa de Pós-Graduação em Agronomia, Universidade Estadual do Centro Oeste, Unicentro, Guarapuava - PR, larissaromaosaito@gmail.com.

${ }^{3}$ Eng ${ }^{0}$ Agrícola, Dr., Programa de Pós-Graduação em Engenharia Agrícola, Universidade Estadual do Oeste do Paraná - Unioeste, Cascavel - PR,mmaggi@unioeste.br.

${ }^{4}$ M.Sc., Programa de Pós-graduação em Agronomia, Universidade Estadual do Centro Oeste, Unicentro, Guarapuava - PR, mvwagner@yahoo.com.br.

${ }^{5}$ Graduando em Agronomia, Universidade Estadual do Centro Oeste, Unicentro, Guarapuava - PR, taiareffatti@ hotmail.com.

Recebido pelo Conselho Editorial em: 24-3-2011

Aprovado pelo Conselho Editorial em: 11-5-2012
} 


\section{INTRODUÇÃO}

No período que vai do plantio à colheita, a cultura da batata apresenta alto grau de sensibilidade às condições de solo, cujo preparo é fundamental para seu desenvolvimento e produtividade.

A utilização de sistema de preparo que mobiliza intensamente a camada superficial do solo é prática comum entre os bataticultores. Para BOLLER \& PREDIGER. (2001), em geral, a bataticultura exerce efeitos de degradação do solo pela mobilização exagerada, favorecendo a erosão. GUIBOSHI et al. (2006) descrevem que, além de provocar dano ambiental, o revolvimento excessivo do solo reduz seu potencial produtivo, causa prejuízo econômico e compromete a viabilidade da cultura, principalmente pela redução da porosidade, da taxa de infiltração de água, e a quantidade de água disponível no solo

A adoção de práticas conservacionistas ainda é pouco comum em lavouras de batata, contudo RILEY \& EKEBERG (1998) conduziram pesquisas comparando o cultivo da batata em solo com preparo convencional e o plantio direto em resteva de cevada. Não observaram diferenças significativas quanto à produção e à qualidade dos tubérculos produzidos, concluindo que o plantio direto dessa cultura é uma alternativa viável. FERNANDES et al. (2006) concluíram que o cultivo de batata em solo com preparo reduzido é viável, apresentando vantagens econômicas inerentes aos custos com mecanização em relação ao preparo convencional.

Para SPERA et al. (2009), sistemas que mantêm quantidade adequada de cobertura vegetal sobre o solo, principalmente durante os períodos mais secos, como o plantio direto, são os mais praticados, especialmente em lavouras de cereais, devido à preocupação, cada vez maior, com a conservação do solo. De acordo com FERNANDES et al. (2006), esta prática, em longo prazo, poderá resultar em maior lucratividade, levando-se em conta que as técnicas de conservação do solo e da água são essenciais para manter as características químicas, físicas e biológicas dos solos.

O fungo T. harzianum é um forte colonizador da palha e, como outras espécies de Trichoderma, apresenta uma poderosa atividade de celulase, sendo, por esse motivo, de interesse no controle eficiente de diversos patógenos da raiz. Para LYNCH (1986), deve ser considerado que os resíduos vegetais servem de substrato para organismos do solo que são benéficos ao crescimento das plantas e que, quando um substrato é introduzido no solo, há menos potencial para que se desenvolvam os produtores de patógenos e de fitotoxinas.

O objetivo da pesquisa foi estudar os efeitos do manejo, com diferentes formas de preparo mecanizado do solo, tipos de resteva e infestação do solo com T. harzianum sobre a produtividade e as características dos tubérculos da cultura da batata.

\section{MATERIAL E MÉTODOS}

O estudo foi conduzido em área experimental do Departamento de Agronomia, no Câmpus Cedeteg, da Universidade Estadual do Centro-Oeste - UNICENTRO, em Guarapuava - PR, localizado na latitude $25^{\circ} 23^{\prime} 36^{\prime \prime} \mathrm{S}$ e na longitude $51^{\circ} 27^{\prime} 19^{\prime \prime} \mathrm{W}$, com altitude de aproximadamente $1.025 \mathrm{~m}$. O clima regional é classificado como $\mathrm{Cfb}$ - subtropical mesotérmico úmido, de acordo com a metodologia de classificação climática de Köeppen \& Geiger(1928).

O solo do local é classificado como Latossolo Bruno Distroférrico. A área foi mantida em pousio por aproximadamente 3 anos, tendo sido cultivado trigo no inverno anterior ao plantio. Aproximadamente 90 dias anteriores à instalação do experimento, foram coletadas amostras de solo da camada de 0-20 cm para análise química (Tabela 1). Aos 60 dias antes do plantio, foi realizada a calagem, visando a elevar o $\mathrm{pH}$ do solo para aproximadamente 6,2, conforme preconizado por PULZ et al. (2008), com incorporação por grade aradora. 
TABELA 1. Características químicas do solo da área experimental. Chemical characteristics of the soil in the experimental area.

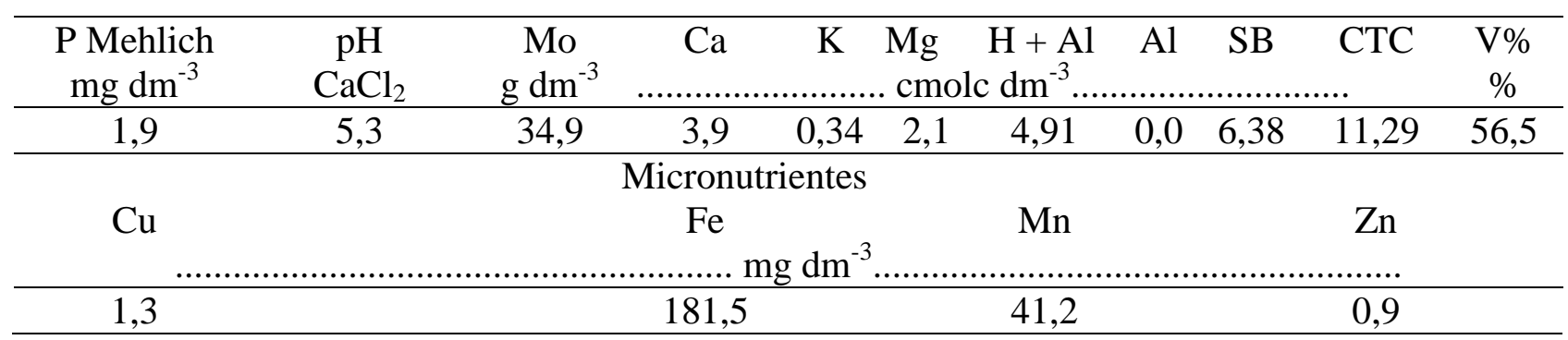

O experimento foi estruturado em delineamento inteiramente casualizado, em parcelas subsubdivididas, em um fatorial $4 \times 5 \times 2$, com quatro repetições. Na parcela principal, foram avaliados quatro diferentes formas de preparo do solo. Na subparcela, cinco diferentes tipos de resteva. Na subsubparcela, avaliaram-se os efeitos da infestação ou não do solo com T. harzianum.

$\mathrm{O}$ fator 1 refere-se às diferentes formas de preparo do solo. O preparo 1 (P1) é considerado preparo-base, sendo realizadas somente as operações de escarificação da área, e utilização de sulcador para abertura dos sulcos para o plantio. No preparo 2 (P2), foi feita a escarificação da área, passagem de grade niveladora e utilização de sulcador. O preparo 3 (P3) constituiu-se da escarificação da área, passagem de enxada rotativa e utilização de sulcador. O preparo 4 (P4) constou de escarificação, passagem de grade niveladora, enxada rotativa e utilização de sulcador, sendo este o preparo convencional praticado pelos bataticultores da região e, por este motivo, considerado como referência ou testemunha neste estudo.

O fator 2 foi constituído pela incorporação de diferentes tipos de resteva (palha) ao solo, simulando o cultivo em sucessão de culturas, em relação aos resíduos culturais remanescentes no solo. Antes da distribuição e de incorporação no solo, a palha utilizada foi posta para secar em local exposto ao sol e protegido das precipitações, até a obtenção de peso constante, para posterior pesagem da quantidade indicada de massa seca para cada tratamento. As quantidades utilizadas foram estimadas de acordo com a média remanescente das culturas de aveia, milho, trigo e feijão em lavoura convencional, e os diferentes tipos de palha foram depositados em área já totalmente escarificada para posterior incorporação.

As quantidades de resteva utilizadas foram: $4 \mathrm{tha}^{-1}$ de aveia-preta (R1), $6 \mathrm{t} \mathrm{ha}^{-1}$ de milho (R2), $3 \mathrm{t} \mathrm{ha}^{-1}$ de trigo (R3) e $3 \mathrm{t} \mathrm{ha}^{-1}$ de feijão (R4), considerando resultados de pesquisa apresentados por GABRIEL FILHO et al. (2004) para trigo, FREDDI et al. (2009) para milho, SORATTO \& CRUSCIOL (2008) para aveia-preta e JADOSKI et al. (2000) para feijão. No manejo-testemunha (R5), não foi incorporada palha, contudo os procedimentos de preparo do solo foram realizados normalmente.

O fator 3 está relacionado com a infestação (I) do solo por T. harzianum, e onde não foi realizada a infestação (NI). A infestação foi realizada com pulverizador costal, aplicando-se $1,0 \mathrm{~L} \mathrm{ha}^{-1}$ de produto comercial sobre os tubérculos no sulco de plantio e nova aplicação com $0,5 \mathrm{~L} \mathrm{ha}^{-1}$ do mesmo produto na superfície do solo próximo às plantas, no momento que antecedeu a realização da prática da amontoa, aos 30 dias após o plantio (DAP). Foi utilizado o produto comercial Trichodermil SC Organic constituído de conídios de fungo e inerte orgânico de cepa de T. harzianum. Onde não foi realizada a infestação, procedeu-se apenas à aplicação de fungicida no sulco de plantio.

O plantio da batata foi realizado no dia 19 de dezembro de 2009, utilizando-se da cultivar Ágata, semente certificada, de primeira geração (G1), produzida pela EMBRAPA na estação experimental de Canoinhas - SC. Foram utilizados tubérculos-semente do tipo 2 (diâmetro entre 40 e $50 \mathrm{~mm}$ ), que foram distribuídos manualmente nos sulcos previamente abertos, em uma profundidade de aproximadamente $0,18 \mathrm{~m}$ no solo. A adubação, realizada no sulco, no dia anterior 
ao plantio, foi feita com 3,3 $\mathrm{tha}^{-1}$ da fórmula NPK 4-14-8, utilizando-se de uma adubadora mecânica de distribuição linear.

As parcelas experimentais foram compostas por quatro fileiras de plantas com $5,0 \mathrm{~m}$ de comprimento e espaçamento de $0,8 \mathrm{~m}$ entre fileiras e de $0,25 \mathrm{~m}$ entre plantas na fileira. A densidade de plantio foi de 50.000 tubérculos por hectare. Consideraram-se como área útil as duas fileiras centrais de cada parcela, com exceção de $0,50 \mathrm{~m}$ em suas extremidades, mantidos como bordadura, juntamente com as fileiras laterais.

A amontoa foi realizada 30 dias após o plantio (DAP), com auxílio de uma enxada rotativa adaptada para tal fim, constando da movimentação do solo, formando um camalhão próximo às plantas, com o objetivo de estimular a tuberização, controlar o esverdeamento dos tubérculos, a infestação das plantas daninhas e proteger as plantas dos fitopatógenos e insetos, conforme salientam FERNANDES et al. (2006).

O tratamento fitossanitário foi realizado tendo como base o manejo utilizado em lavouras comerciais da região, com pulverização de fungicidas de forma preventiva para as doenças de pinta-preta (Alternaria solani) e requeima (Phytophthora infestans). Foram realizadas duas aplicações dos produtos com ingrediente ativo (i.a.) Mancozeb para pinta-preta e dos produtos (i.a.) Azoxystrobin, Tebuconazole e Iprodione, para requeima, respectivamente. Este controle preventivo foi realizado em todas as parcelas, independentemente do tratamento com infestação por $T$. harzianum no solo, pois, segundo o fabricante, este fungo não é afetado pelos tratamentos fitossanitários convencionalmente utilizados para a cultura.

O controle de insetos foi realizado com alternância entre os produtos (i.a) Tiametoxam, Carbaril, Cloripirifós e Lambda-cialotrina, com média de duas aplicações semanais. Ambos os produtos inseticidas e fungicidas são registrados para a cultura da batata e foram utilizados nas doses recomendadas. $\mathrm{O}$ controle de plantas invasoras foi realizado manualmente quando necessário.

Aos 95 DAP, a cultura foi dessecada com utilização de produto (i.a.) Paraquat, visando a uniformizar a maturação das plantas. A colheita dos tubérculos na área útil da parcela ocorreu no dia 15 de abril de 2010, aos 116 DAP. Os tubérculos colhidos foram encaminhados para as avaliações de produtividade e classificação, no laboratório da Unidade de Pesquisa em Produção de Batata e Microclima para a Agricultura da Unicentro, nas proximidades da área experimental.

A produtividade foi obtida pela pesagem dos tubérculos das plantas colhidas nos $8 \mathrm{~m}$ da área útil de cada unidade experimental. Após a colheita, os tubérculos foram lavados e pesados, e os resultados, calculados com projeção para $\mathrm{kg} \mathrm{ha}^{-1}$, considerando um stand de 50.000 plantas, resultante dos espaçamentos de plantas utilizados no plantio.

A classificação dos tubérculos foi baseada na Portaria $n^{\circ}$ 69, de 21 de fevereiro de 1995, do Ministério da Agricultura, Pecuária e Abastecimento (MAPA), conforme Tabela 2. O parâmetro considerado foi a medida do diâmetro do tubérculo, que foi determinada com auxílio de um paquímetro digital, em todos os tubérculos colhidos.

TABELA 2. Classes ou Calibres de acordo com o maior diâmetro transversal do tubérculo da batata. Gauges or classes according to the largest transverse diameter of the potato tuber.

\begin{tabular}{cl}
\hline Classes & Maior Diâmetro Transversal $(\mathrm{mm})$ \\
\hline 1 & Maior ou igual a 85 \\
2 & Maior ou igual a 45 e menor que 85 \\
3 & Maior ou igual a 33 e menor que 45 \\
4 & Menor que 33 \\
\hline
\end{tabular}


A avaliação estatística foi realizada por teste de normalidade de médias, análise de variância e teste de comparação de médias, pelo método de Tukey, a 5\% de probabilidade, e teste (t) de Student, para o caso de pares de médias, utilizando-se do software ASSISTAT versão 7.5 beta 2010.

\section{RESULTADOS E DISCUSSÃO}

Na Tabela 3, são apresentados os resultados referentes às médias de produtividade em relação às formas de preparo utilizados em campo.

TABELA 3. Produtividade da cultura da batata, em função de diferentes formas de preparo do solo. Yield of potato tubers, considering the soil tillage.

\begin{tabular}{lc}
\hline \multicolumn{1}{c}{ Formas de preparo } & ${\text { Produtividade } \mathrm{kg} \mathrm{ha}^{-1}}^{-1}$ \\
$\mathrm{P} 1=$ Escarificação e sulcamento & $50.086 \mathrm{a}$ \\
$\mathrm{P} 2=\mathrm{P} 1+$ Grade niveladora & $55.222 \mathrm{a}$ \\
$\mathrm{P} 3=\mathrm{P} 1+$ Enxada rotativa & $50.572 \mathrm{a}$ \\
$\mathrm{P} 4=\mathrm{P} 1+$ Grade niveladora + Enxada rotativa & $38.624 \mathrm{~b}$ \\
\hline DMS & 11.180
\end{tabular}

A média geral de produtividade do experimento foi de $48.626 \mathrm{~kg} \mathrm{ha}^{-1}$, acima da média regional, que de acordo com SEAB-DERAL (2007) é de aproximadamente 22.000 a $30.000 \mathrm{~kg} \mathrm{ha}^{-1}$. Em pesquisa com diferentes preparos de solo e com adição de palha, JOUKHADAR (2006) obteve $32.000 \mathrm{~kg} \mathrm{ha}^{-1}$ como média geral de produtividade, sendo destacados pelos autores os efeitos positivos de preparos com redução da mobilização do solo.

Com a análise dos efeitos da forma de preparo do solo, observa-se que o preparo 4 , onde se realizou a maior mobilização do solo, utilizando-se, além do preparo-base, os equipamentos grade niveladora e enxada rotativa, resultou na menor média de produtividade em relação aos demais tratamentos. É pertinente considerar que este é o procedimento de mecanização de uso mais generalizado nas áreas de produção de batata no Brasil, conforme destacam RAGASSI et al. (2009).

Este resultado demonstra que é possível aplicar-se manejos menos agressivos ao solo para a implantação das lavouras da cultura, representando um ganho ambiental, associado também a aspectos de ganhos financeiros pela expectativa de incremento de produção, associada à redução de custos com a mecanização. FONTES et al. (2007) salientam que é prática comum entre os bataticultores a utilização de sistema de preparo que mobiliza intensamente a camada superficial do solo; além disso, os autores citam diferentes pesquisas que alertam que esta mobilização intensiva pode ocasionar sérios danos ao solo, comprometendo a conservação da fertilidade e, inclusive, a viabilidade da cultura.

Os resultados inerentes ao preparo reduzido do solo, com uso apenas do escarificador anterior ao sulcamento da área, realizado no preparo-base (P1), estão de acordo com o descrito por CARVALHO FILHO et al. (2007). Estes autores descrevem o escarificador como equipamento adequado ao sistema conservacionista por proporcionar elevado índice de rugosidade, gerando menor formação de encrostamento superficial, reduzindo ou retardamento o escoamento superficial e aumentando a infiltração e o armazenamento de água no perfil de solo explorado. Características associadas ao incremento de produtividade da cultura da batata demonstram o alto grau de sensibilidade à baixa disponibilidade de água.

Com relação às características físicas, a área experimental, considerando-se, neste caso, a densidade do solo determinada a 10 e a $30 \mathrm{~cm}$ de profundidade, 60 dias antes do plantio, apresentava os valores iniciais de 1,27 e 1,29 $\mathrm{g} \mathrm{cm}^{-3}$, que passaram a ser de 1,3 e 1,28 $\mathrm{g} \mathrm{cm}^{-3}$, respectivamente, na avaliação realizada 10 dias após a colheita, sem diferenças significativas entre os tratamentos. 
Esta é uma situação que demonstra que as características modificadas pelo preparo inicial mecanizado, que tornam o solo fisicamente mais adequado ao cultivo, tendem a retornar às condições anteriores. A tendência observada de aumento na densidade da camada mais superficial pode ser, em parte, entendida como uma consequência de várias atividades de manejo, como preparo mecanizado inicial, realização de amontoa e processo de colheita, que além da ação mecânica do arranquio exige, ainda, a circulação de pessoas e máquinas para o recolhimento e o transporte dos tubérculos.

Neste caso, pode-se inferir, ainda, que o efeito ocasionado pela adição e incorporação de palhas sobre a melhoria de características físicas do solo, é um processo lento, e que para os tipos e quantidades de palhas utilizadas e nas condições de manejo aplicadas no experimento, não se evidenciam efeitos significativos com uma única aplicação de resteva em apenas um ciclo de cultivo.

A avaliação estatística dos dados experimentais não demonstrou significância do efeito do manejo com infestação do solo por $T$. harzianum sobre a produtividade de tubérculos. Neste caso, é de se considerar que o fungo não exerce efeito direto sobre o incremento da produtividade de tubérculos de batata. Estes resultados contrariam, de certa forma, as expectativas de possíveis aumentos de produtividade destacadas por HARMAN (2000). Embora LOUZADA et al. (2009) acrescentem que este fungo desenvolve ação direta no controle de patógenos, apresentando somente ação indireta sobre a produtividade das plantas e melhor exploração do solo pelo sistema radicular. Nestas condições, torna-se evidente a necessidade de ampliação do número de estudos sobre a utilização do fungo na cultura da batata, devido serem encontradas ainda poucas informações na literatura acerca desta técnica.

Na Tabela 4, são apresentados os resultados referentes às médias de produtividade em relação aos efeitos dos diferentes tipos de resteva utilizados no cultivo.

TABELA 4. Produtividade da cultura da batata, em função de diferentes tipos de resteva. Yield of potato considering different type of stubble.

\begin{tabular}{cc}
\hline Tipo de Resteva & Produtividade kg ha $^{-1}$ \\
\hline Aveia-preta & $48.808 \mathrm{a}$ \\
Milho & $50.636 \mathrm{a}$ \\
Trigo & $53.720 \mathrm{a}$ \\
Feijão & $49.690 \mathrm{a}$ \\
Sem resteva & $40.275 \mathrm{~b}$ \\
\hline DMS & 5.966
\end{tabular}

Médias seguidas pela mesma letra não diferem estatisticamente entre si, pelo teste de Tukey $(\mathrm{p} \geq 0,05)$.

Observa-se que a cultura responde ao manejo da resteva no solo, sendo que ocorreu a redução de aproximadamente $8.000 \mathrm{~kg} \mathrm{ha}^{-1}$ na produtividade total de tubérculos quando o cultivo foi realizado na condição do tratamento-testemunha, sem incorporação de resteva. Assim, como o preparo do solo com um menor número de operações mecânicas, o manejo dos restos culturais, incorporando resteva ao solo, é um aspecto a ser considerado no planejamento das áreas de produção de batata, pois demonstra possibilidade de redução de gastos com adubação química, sendo este um componente expressivo do custo de produção da cultura, além dos ganhos ambientais e edáficos associados à adição de matéria orgânica ao solo.

Em análise realizada dez dias após a colheita, verificou-se que, nas parcelas-testemunha, que não receberam incorporação de palha, o teor de Matéria orgânica (M.O.) passou de 34,9 para 35,6, e nas parcelas com palha incorporada, para $36,8 \mathrm{~g} \mathrm{dm}^{-3}$, respectivamente, sem ocorrência de diferenças entre os tipos de palha e forma de mecanização do solo.

Esta não ocorrência de diferenças significativas entre as parcelas-testemunhas em relação aos tratamentos onde se adicionou palha simulando a presença de resteva no início do ciclo da cultura, 
está em grande parte condicionada a fatores como velocidade de decomposição da palha, características dos restos vegetais presentes na superfície do solo, em toda a área experimental no momento do preparo inicial, processo de absorção e liberação de componentes orgânicos pela cultura, dentre outros, conforme salientam PAVINATO \& ROSOLEN (2008). A não ocorrência de diferenças entre as formas de preparo do solo é uma indicativa de que este processo pode ser realizado de forma reduzida, movimentando menos o solo em relação ao preparo convencional, mesmo quando o manejo engloba a incorporação de determinadas quantidades de resteva ao solo.

JADOSKI et al. (2009) destacam que a massiva maioria dos produtores, associa à mecanização do solo com revolvimento intensivo, e em geral com pouca preocupação com questões de conservação do solo e adição de restos culturais. Por outro lado, os autores verificaram que restevas de culturas como aveia e ervilhaca podem predispor ao aumento de incidência da sarna comum (Streptomyces spp.) nos tubérculos, sendo este um dos principais motivos de os bataticultores manejarem as lavouras geralmente evitando a incorporação de palha ao solo; contudo, este efeito não pode ser generalizado a todas as restevas.

Os resultados da produtividade com relação às interações entre os fatores preparo do solo e tipo de resteva encontram-se na Tabela 5. Observa-se que nas condições do preparo P4, e com o manejo sem utilização de restevas ocorreram as menores produtividades. Esses resultados corroboram os apresentados anteriormente nas Tabelas 3 e 4 , onde se verificam maiores produtividades nos tratamentos onde se reduziu o número de operações de preparo e, consequentemente a mobilização do solo, quando comparado ao manejo realizado no P4, que representa maior revolvimento do solo associando operações de gradagem e enxada rotativa.

Os resultados apresentados na Tabela 5 evidenciam também que a presença de resteva no solo exerce efeitos positivos sobre a produtividade da cultura, destacadamente em condições de manejo convencional de preparo do solo, como é o caso da sequência de operações realizadas no P4, que conforme destacam BOLLER \& PREDIGER (2001), representa o manejo praticado na grande maioria das lavouras de produção de batata.

TABELA 5. Produtividade de tubérculos de batata, considerando a interação entre os fatores formas de preparo do solo e tipo de resteva. Yield of potato tubers, considering the interaction among soil tillage system and type of stubble.

\begin{tabular}{lccccc}
\hline Formas de Preparo & Aveia (R1) & Milho (R2) & Trigo (R3) & Feijão (R4) & $\begin{array}{c}\text { Sem resteva } \\
\text { (R5) }\end{array}$ \\
\hline P1 = Escarificação e sulcamento & $48.972 \mathrm{aA}$ & $45.570 \mathrm{aA}$ & $55.945 \mathrm{aA}$ & $50.484 \mathrm{aA}$ & $49.458 \mathrm{aA}$ \\
P2 = P1 + Grade niveladora & $52.264 \mathrm{aA}$ & $52.565 \mathrm{aA}$ & $57.466 \mathrm{aA}$ & $54.345 \mathrm{aA}$ & $59.470 \mathrm{aA}$ \\
P3 = P1 + Enxada rotativa & $49.277 \mathrm{aA}$ & $56.641 \mathrm{aA}$ & $50.577 \mathrm{aA}$ & $47.860 \mathrm{aA}$ & $48.503 \mathrm{aA}$ \\
P4 = P1 + Grade niveladora + & $44.719 \mathrm{aA}$ & $47.768 \mathrm{aA}$ & $50.893 \mathrm{aA}$ & $46.072 \mathrm{aA}$ & $34.576 \mathrm{bB}$ \\
Enxada rotativa & & &
\end{tabular}

DMS para colunas $=14,296$

DMS para linhas $=11,932$

Médias seguidas pela mesma letra não diferem estatisticamente entre si, pelo teste de Tukey $(\mathrm{p} \geq 0,05)$ (letras minúsculas: coluna; letras maiúsculas: linha).

Tal resultado pode estar relacionado com as condições de redução da qualidade física do solo na camada em que irá desenvolver-se o sistema radicular da cultura, pela desestruturação ocasionada pelo excesso de mobilização e reduzida quantidade de material orgânico em decomposição, com efeitos negativos, inclusive sobre a disponibilidade de nutrientes para a planta, conforme salientam DANTAS et al. (2009). Para RAGASSI et al. (2009), a compactação profunda causada pelo uso intensivo de máquinas e implementos durante o preparo convencional do solo, provoca a ruptura de agregados, com degradação da qualidade do solo, afetando o rendimento da cultura da batata. 
Verificou-se interação significativa para o fator infestação com T. harzianum em relação ao tamanho e à porcentagem de embonecamento dos tubérculos. Os valores médios da classificação de tubérculos produzidos no experimento são apresentados na Figura 1. Os resultados demonstram que a produção de tubérculos com diâmetro superior a $85 \mathrm{~mm}$ (classe 1) foi inferior a 1\%, sendo detectado na colheita que aproximadamente $100 \%$ dos tubérculos enquadrados nesta classe foram também classificados como embonecados, com deformação do formato normal para a cultivar e produzidos em parcelas onde foi realizada a infestação do solo com T. harzianum.

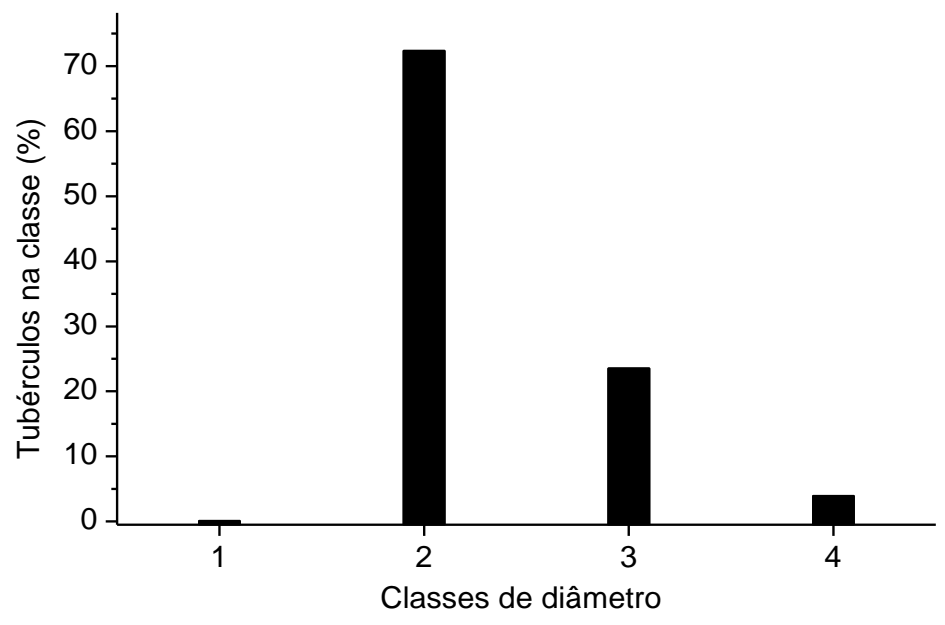

FIGURA 1. Médias gerais de classificação de tubérculos de batata cultivada com diferentes formas de preparo do solo, tipo de resteva e infestação do solo com T. harzianum. Metodologia MAPA (1995). Overall means of classification of potato tubers grown under different forms of tillage, stubble and type of soil infestation with $T$. harzianum. MAPA Methods (1995).

Na classe 2 (diâmetro entre $45 \mathrm{~mm}$ e $85 \mathrm{~mm}$ ), o maior número de tubérculos presentes foram produzidos sem a infestação do solo com T. harzianum. Já em relação às classes 3 (diâmetro entre $33 \mathrm{~mm}$ e $45 \mathrm{~mm}$ ) e 4 (diâmetro <33 mm), as maiores percentagens de tubérculos presentes foram produzidas em parcelas com a infestação do fungo (Tabela 6). Destaca-se que, dentro da classe 2, verificou-se que 2,44\% dos tubérculos apresentavam sintomas de embonecamento quando cultivados em parcelas infestadas por $T$. harzianum, sendo este valor estatisticamente superior aos $0,16 \%$ verificados para produção em solo sem infestação pelo fungo.

A respeito destes resultados, é pertinente considerar que a infestação com o fungo pode ter ocasionado alterações no desenvolvimento dos tubérculos em relação às características normais da cultivar, já que os maiores tubérculos e a maior taxa de embonecamento foram observados nos tratamentos com a presença do Trichoderma. ARGUMEDO-DELIRA et al. (2009) destacam que fungos do gênero Trichoderma podem produzir diversos metabólicos secundários, dentre os quais se encontram hormônios de crescimento, como auxinas e giberelinas. Neste caso, existindo associação entre o fungo e os tubérculos ou as raízes, estes hormônios podem ter desenvolvido interações com o metabolismo das plantas e, consequentemente, no desenvolvimento dos tubérculos. O próprio embonecamento, que é considerado um defeito de ordem fisiológica, pode também ser uma consequência desencadeada por este fator. Contudo, este aspecto exige estudos mais aprofundados.

Estes resultados indicam que a infestação do fungo no solo exerce influência sobre as características dos tubérculos e demonstram interação deste fungo com a cultura, pois conforme MELLO et al. (2003) a cultivar Ágata apresenta como característica marcante a uniformidade dos tubérculos produzidos. Neste caso, a presença do fungo tendeu a diminuir o tamanho dos tubérculos, que na classificação passam a migrar da classe 2 para a classe 3, fato que prejudica o valor econômico da produção. Com relação à insignificante presença de tubérculos na classe 1, 
JADOSKI et al. (2009) verificaram resultados similares e consideram que, possivelmente, a cultivar Ágata não apresente como característica produzir tubérculos com diâmetro superior a $85 \mathrm{~mm}$.

TABELA 6. Porcentagem de tubérculos de batata na Classe 2 (diâmetro entre 45 e $85 \mathrm{~mm}$ ), em função da infestação do solo com T.harzianum. Percentage of potato tubers - Class 2, considering the factor of soil infestation with T.harzianum.

\begin{tabular}{lcccc}
\hline Trichoderma harzianum & \multicolumn{4}{c}{$\%$ tubérculos } \\
\hline Não infestado & classe 1 & classe 2 & classe 3 & classe 4 \\
Infestado & - & 74,87 & 22,10 & 3,02 \\
DMS & 0,41 & $69,92^{*}$ & $25,01^{*}$ & $4,66^{*}$ \\
\hline NMS & - & 3,032 & 2,584 & 1,279
\end{tabular}

Na coluna, * representa diferenças estatisticamente significativas (pelo teste t-Student, $\mathrm{p}<0,05$ ).

Os efeitos verificados devido à utilização do fungo neste experimento destacam-se ao se considerar que, em geral, o embonecamento é analisado como consequência de estresse fisiológico, conforme descreve PEREIRA et al. (2010), e não por efeito biológico, como a presença do $T$. harzianum. Com relação a este fungo, seus efeitos ainda representam novidade no meio agrícola, cujos conhecimentos sobre as culturas ainda são restritos, especialmente para a batata. Considerando-se a rápida disseminação de sua adoção em diferentes culturas, é importante a realização de novas pesquisas, visando a estabelecer critérios que justifiquem sua aplicação e possibilitem o manejo adequando das lavouras infestadas.

\section{CONCLUSÕES}

O preparo convencional do solo para a cultura da batata, com utilização de escarificador, enxada rotativa, grade e sulcador, pode ser realizado de forma reduzida, eliminando a operação com enxada rotativa ou gradagem.

O cultivo de batata em solo com restos culturais de trigo, aveia-preta, milho, ou feijão em sistema de preparo reduzido, eliminando-se a operação com enxada rotativa ou grade niveladora, incrementa a produtividade da cultura, em comparação ao cultivo com preparo convencional e sem a presença de restos culturais.

O cultivo de batata utilizando preparo convencional com elevado revolvimento do solo, associado à ausência de restos culturais incorporados, demonstra ser inadequado, por ocasionar redução da produtividade da cultura.

O uso do fungo T. harzianum infestado ao solo demonstrou ocasionar alterações no formato dos tubérculos de maior tamanho e não ocasiona efeitos de aumento de produtividade da cultura da batata.

\section{REFERÊNCIAS}

ARGUMEDO-DELIRA, R.; ALARCON, A.; FERRERA-CERRATO, R.; PENA-CABRIALES, J.J. El género fúngico Trichoderma y su relación con los contaminantes orgánicos e inorgánicos. Revista Internacional de Contaminación Ambiental, México, v.25, n.4, p.257-269, set./dez., 2009.

BOLLER, W.; PREDIGER, L.J. Cultivo da batata (Solanum tuberosum L.) em função de diferentes sistemas de preparo e condições de cobertura do solo. Engenharia Agrícola, Jaboticabal, v.21, p.174-179, set./dez., 2001.

CARVALHO FILHO, A.; CENTURION, J.F.; SILVA, R.P.; FURLANI, C.E.A.; CARVALHO, L.C.C. Métodos de preparo do solo: Alterações na rugosidade do solo. Engenharia Agrícola, Jaboticabal, v.27, n.1, p.229-237, jan./abr. 2007. Disponível em:

http://www.scielo.br/pdf/eagri/v27n1/17.pdf. Acesso em: 21 nov. 2010. 
DANTAS, V.B.; PINTO FILHO, J.L. O.; PEREIRA, J.O. Avaliação do efeito da palhada de milho sobre as propriedades físico-químicas do solo. Revista Verde, Mossoró, v.4, n.2, p.85-92, abr./jun. 2009. Disponível em: http://www.gvaa.com.br/revista/index.php/RVADS/article/viewFile/175/175. Acesso em: 13 out. 2010.

FERNANDES, H.A.; OLIVEIRA, A.D. de; FONTES, P.C.R.; CAMILO, A.J.; RINALDI, P.C.N. Avaliação da cultura da batata instalada por uma plantadora adaptada para trabalhar em sistemas de plantio direto e cultivo mínimo. Revista Ceres, Viçosa, v.53, n.305, p.65-73, nov./dez., 2006.

FONTES, P.C.R.; NUNES, J.C.S.; FERNANDES, H.C.; ARAUJO, E.F. Características físicas do solo e produtividade da batata dependendo de sistemas de preparo do solo. Horticultura Brasileira, Brasília, v.25, n.3, p. 355-359, jul./set., 2007.

FREDDI, O. da S.; CENTURION, J.F.; DUARTE, A.P.; LEONEL, C.L. Compactação do solo e produção de cultivares de milho em Latossolo Vermelho. I - características de planta, solo e índice S. Revista Brasileira de Ciência do Solo, Viçosa, v.33, n.4, p.793-803, jul./ago. 2009.

GABRIEL FILHO, A.; SILVA, S.L.; MODOLO, A.J.; SILVEIRA, J.C.M. Desempenho de um trator operando em solo com diferentes tipos de cobertura vegetal. Engenharia Agrícola, Jaboticabal, v.24, n.3, p.781-789, set./dez. 2004. Disponível em: http://www.scielo.br/pdf/eagri/v24n3/a32v24n3.pdf . Acesso em: 14 nov. 2010.

GUIBOSHI, M.L.; RODRIGUES, L.H.A.; LOMBARDI NETO, F. Sistema de suporte à decisão para recomendação de uso e manejo da terra. Revista Brasileira de Engenharia Agrícola e Ambiental, Campina Grande, v.10, n.4, p.861-866, out./dez., 2006.

HARMAN, G.E. Myths and dogmas of biocontrol changes in perceptions derived from research on Trichoderma harzianum T-22. Plant Disease, Saint Paul, v.84, p.377-392, 2000.

JADOSKI, S.O.; CARLESSO, R.; WOISCHICK, D.; PETRY, M.T.; FRIZZO, Z. População de plantas e espaçamento entre linhas do feijoeiro irrigado. II: Rendimento de grãos e componentes do rendimento. Ciência Rural, Santa Maria, v.30, n.4, p.567-573, set./dez. 2000.

JADOSKI, S.O.; MAGGI, M.F.; LIMA, A. dos S.; BRUNETTA, L.; WAZNE, R. Sucessão de culturas na fitossanidade e produtividade da cultura da batata (Solanum tuberosum L.). Pesquisa Aplicada \& Agrotecnologia, Guarapuava, v.2, n.1, p.161-172, jan./abr., 2009.

JOUKHADAR, S.I. Métodos de preparo do solo e impacto na produtividade da batateira em Ibicoara-BA. 2006. 60 f. Dissertação (Mestrado em Agronomia) - Universidade Estadual do Sudoeste da Bahia, Vitória da Conquista, 2006.

KÖEPPEN, W.; GEIGER, R. Klimate der Erde. Gotha: Verlag Justus Perthes. 1928. Wall-map 150 $\mathrm{cm} \times 200 \mathrm{~cm}$.

LYNCH, J.M. Biotecnologia do solo. Fatores microbiológicos na produtividade agrícola. São Paulo: Manole, 1986. 190 p.

LOUZADA, G.A. de S.; CARVALHO, D.D.C.; MELLO, S.C.M.; LOBO JUNIOR, M.;

MARTINS, I.; BRAÚNA. L.M. Potencial antagônico de Trichoderma spp. originários de diferentes agroecossistemas contra Sclerotinia sclerotiorum e Fusarium solani. Biota Neotropica, Campinas, v.9, n.3, p.145-149, set./dez., 2009.

MELO, P.C.T.; GRANJA, N.P.; MIRANDA FILHO, H.S.; SUGAWARA, A.C.; OLIVEIRA, R.F. Análise do crescimento da cultivar de batata “Ágata”. Batata Show, Itapetininga, v.1, n.8, p.14-21, dezembro, 2003.

PAVINATO, P.S.; ROSOLEM, C.A. Disponibilidade de nutrientes no solo: decomposição e liberação de compostos orgânicos de resíduos vegetais. Revista Brasileira de Ciência do Solo, Viçosa, v.32, n.3, 2008. 
PEREIRA, A. da S.; BERTONCINI, O.; CASTRO, C. M.; ELO, P. E. D. et al. BRS ANA: cultivar de batata de duplo propósito. Horticultura Brasileira, Brasília, v.28, n.4, p.501-505, out./dez., 2010. Disponível em: http://www.scielo.br/pdf/hb/v28n4/21.pdf. Acesso em: 02 fev. 2011.

PULZ, L.P.; CRUSCIOL, C.A.C.; LEMOS, L.B.; SORATTO, R.P. Influência de silicato e calcário na nutrição, produtividade e qualidade da batata sob deficiência hídrica. Revista Brasileira de Ciência do Solo, Viçosa-MG, v.32, n.4, p.1.651-1.659, jul./ago., 2008.

RAGASSI, C.F.; FAVARIN, J. L.; SHIRAISHI, F. A.; MOITA, A. W.; SAKO, H.; MELO, P.C.T. Efeito da descompactação profunda de solo na produção da cultura da batata. Horticultura Brasileira, v.27, n.4, p.484-489, out./dez., 2009. Disponível em: http://www.scielo.br/pdf/hb/v27n4/14.pdf. Acesso em: 07 ago. 2010.

RILEY, H.; EKEBERG, E. Effects of depth and time of ploughing on yields of spring cereals and potatoes and on soil properties of a morainic loam soil. Acta Agriculturae Scandinavica - Section B Soil and Plant Science, Tokyo, v.48, p.193-200, 1998.

SEAB-DERAL. Área e produção agrícola no Estado do Paraná e comparativo com o Brasil. Curitiba: Secretaria de Agricultura e Abastecimento, 2007. 66 p.

SORATTO, R.P.; CRUSCIOL, C.A.C. Produção de fitomassa e acúmulo de nutrientes pela aveiapreta em função da aplicação de calcário e gesso em superfície na implantação do sistema plantio direto. Ciência Rural, Santa Maria, v.38, n.4, p.928-935, Nov./dez., 2008.

SPERA, S.T.; SANTOS, H.P. dos; FONTANELI, R.S.; TOMM, G.O. Integração lavoura e pecuária e os atributos físicos de solo manejado sob sistema plantio direto. Revista Brasileira de Ciência do Solo. Viçosa, v.33, n.1, p.129-136, jan./fev., 2009. 